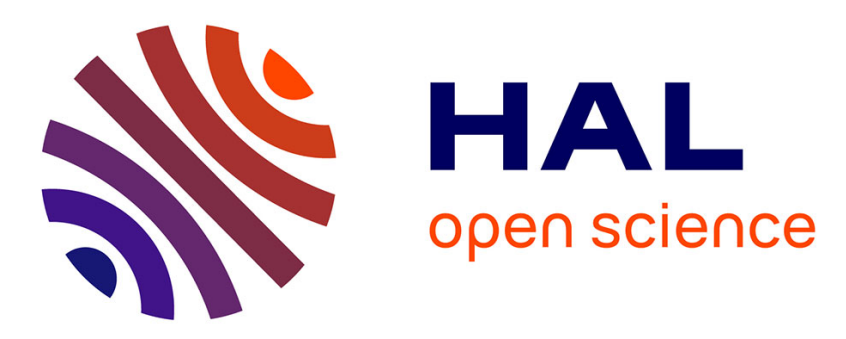

\title{
Hybrid excitation synchronous permanent magnets synchronous machines optimally designed for hybrid and full electrical vehicle
}

\author{
Emmanuel Hoang, Michel Lécrivain, Sami Hlioui, Mohamed Gabsi
}

\section{- To cite this version:}

Emmanuel Hoang, Michel Lécrivain, Sami Hlioui, Mohamed Gabsi. Hybrid excitation synchronous permanent magnets synchronous machines optimally designed for hybrid and full electrical vehicle. 8th International Conference on Power Electronics - ECCE Asia - May 30-June 3, 2011, The Shilla Jeju, Korea, May 2011, Jeju, South Korea. hal-00626615

\section{HAL Id: hal-00626615 https://hal.science/hal-00626615}

Submitted on 26 Sep 2011

HAL is a multi-disciplinary open access archive for the deposit and dissemination of scientific research documents, whether they are published or not. The documents may come from teaching and research institutions in France or abroad, or from public or private research centers.
L'archive ouverte pluridisciplinaire HAL, est destinée au dépôt et à la diffusion de documents scientifiques de niveau recherche, publiés ou non, émanant des établissements d'enseignement et de recherche français ou étrangers, des laboratoires publics ou privés. 


\title{
Hybrid excitation synchronous permanent magnets synchronous machines optimally designed for hybrid and full electrical vehicle
}

\author{
E. Hoang ${ }^{1}$, M. Lécrivain ${ }^{2}$, S. Hlioui ${ }^{2}$, M. Gabsi ${ }^{1}$ \\ ${ }^{1}$ SATIE, ENS Cachan, CNRS, Universud, \\ ${ }^{2}$ SATIE, CNAM, ENS Cachan, CNRS \\ 61, av Président Wilson, F-94230 Cachan, France \\ hoang@satie.ens-cachan.fr
}

\begin{abstract}
In this paper, the performances of a hybrid excitation flux switching permanent magnets synchronous machine (HEFSSM) that have been optimally designed for a hybrid electric vehicle (HEV) application are shown. The different losses: copper losses and iron losses are computed for the European Normalized Driving Cycle (NEDC) by taking into account all operating points in the torque-speed plan. Finally, the optimization problem of such hybrid excitation machine for a given driving cycle is discussed.
\end{abstract}

Index Terms--Hybrid excitation, synchronous machine, flux switching, driving cycle, HEV application, iron losses.

\section{INTRODUCTION}

High efficiency, high power factor, high Torque/Volume ratio, high torque and speed operating points to be reached, these are some constraints that have to be fulfilled by the electrical machine when it is designed for almost of embedded applications. For the hybrid electrical vehicle (HEV) or full electrical vehicle (EV) application case, in addition to previously mentioned constraints, the number of operating points in the torque/speed plan to be reached by the electric machine is very important and scattered as we can notice in the figure 1. In this figure we show an example of two driving cycles one is for "road use" and the other for "urban use". Both of these cycles are composed by approximately 1000 operating points to be performed by the electrical machine in the HEV application.

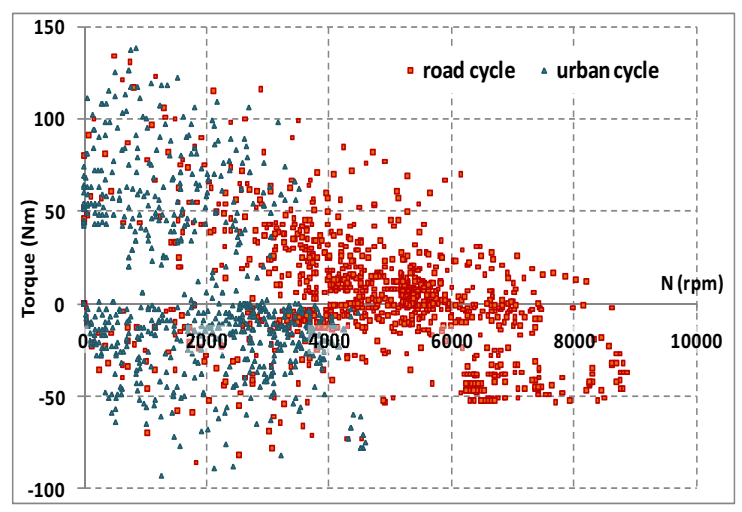

Fig. 1: Two driving cycles for HEV application

In order to satisfy these different constraints various classical electrical machines structures and technologies are studied like the induction machines, the wound rotor synchronous machine, the permanent magnets synchron- ous machines, the switched reluctance machines. In another side, special electrical machines like the hybrid excitation one are studied for these applications and seems to be an interesting solution [3] while it combines the advantages of the permanent magnets machines and wound rotor synchronous machines. In fact, in different operating regions, low speed and low torque operating points, only permanent magnets will be used to produce the needed excitation flux thus the efficiency will be important. However, if the machine has, for example, to reach high torque operating points a DC current will be applied to the excitation coils in order to increase the total excitation flux, thus to increase the torque value.

In this paper, we will firstly present different structures of hybrid excitation machines that are classified by the permanent magnet position in the machine. The studied hybrid excitation machine, hybrid excitation flux switching machine, will also be presented. Secondly, the considered driving cycle will be presented. Thirdly, the different electromagnetic models that are exploited to calculate the performances of this structure and the different losses are given. Fourthly, will be calculated on the NEDC driving cycle the performances of the HFSM are presented and discussed. Finally, the optimization problem is presented and discussed.

\section{HYBRID EXCITATION SYNCHRONOUS MACHINES}

\section{A. Hybrid excitation synchronous machines with global} $D C$ excitation coils and permanent magnets in the rotor.

These hybrid excitation machines are based on classical permanent magnets machines. Permanent magnets are in the rotor and the excitation coils are global coils as we can see on figures 2,3 and 4 [1, 2, 3]. For example, the structure of the hybrid synchronous machine presented in figure 2 is composed by a rotor composed by laminated parts, solid iron parts and permanent magnet in focusing configuration. The stator is also composed by laminated and solid iron parts, classical armature windings and additional DC excitation coils situated above the armature end windings. Thanks to the excitation coils it is possible to modulate the total excitation flux in the air gap region of the machine thus the EMF of the machine as it is shown on figure 5. Another benefit of these additional excitation coils is that they make possible to improve the effectiveness of the machine in different operating regions in the Torque - Speed plan. The figure 6 
shows the efficiency map of a hybrid excitation machine. It can be seen that for the most frequently used operating points the effectiveness of the machine is important (higher than $86.7 \%$ ) while only permanent magnets are used in order to generate the total excitation flux. However, for the other operating points the DC excitation coils are used either to increase the total excitation flux and reach high speed torque operating points either to reduce the total excitation flux and reach high speed operating points.

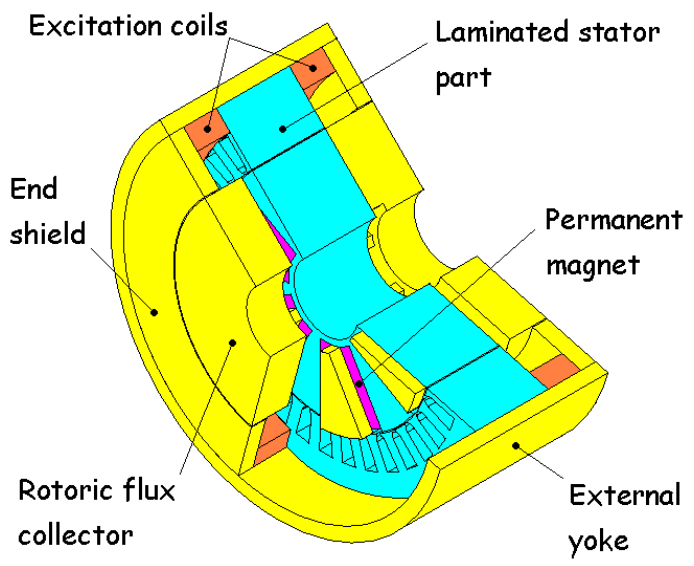

Fig.2: Focusing flux permanent magnet synchronous machine with DC global excitation coils

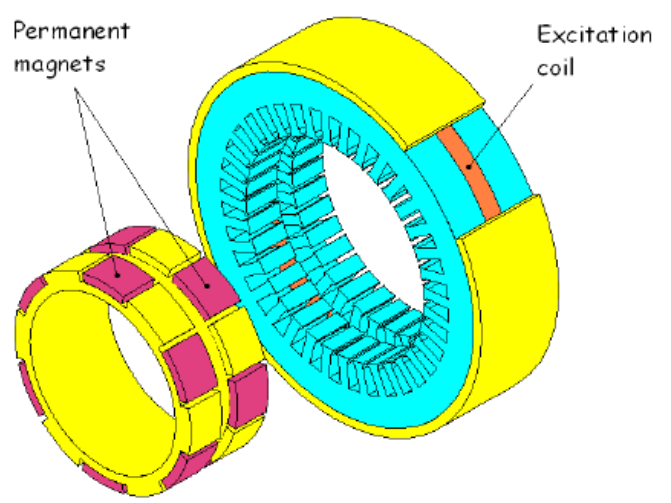

Fig.3: Consequent-Pole Permanent-Magnet Machine with global excitation coil

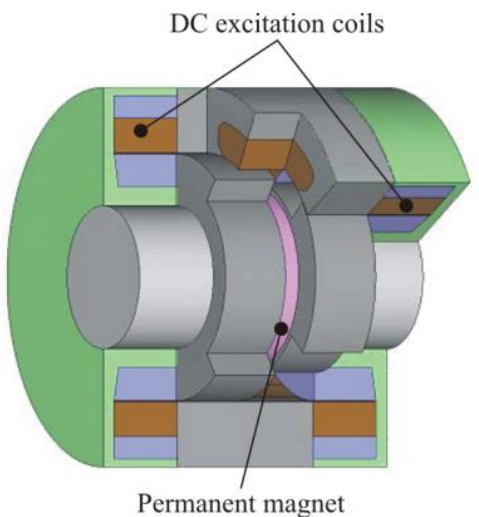

Fig.4: Synchronous Machine with Powdered Iron Core and global excitation coils

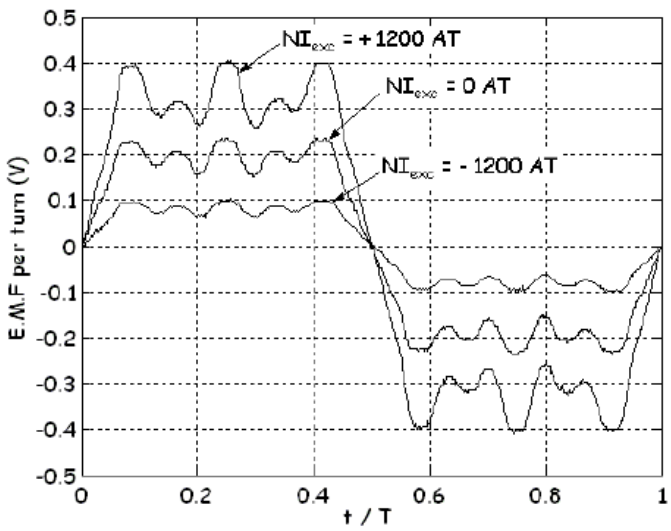

Fig. 5: EMF variations [2]

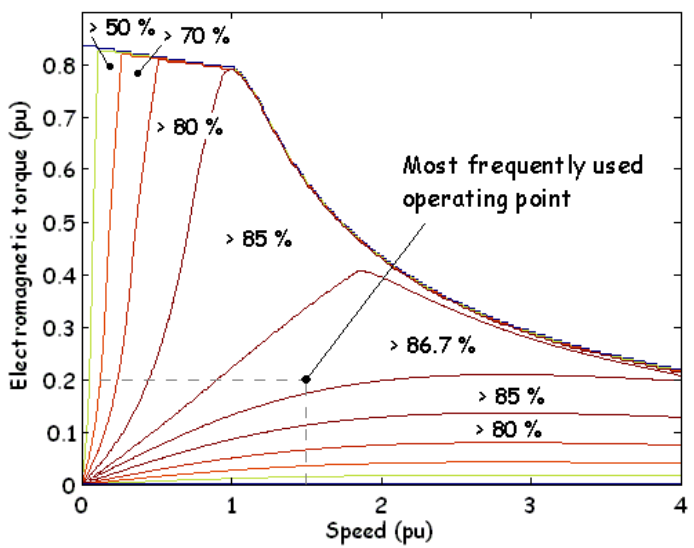

Fig. 6: Efficiency map [2]

\section{B. Hybrid excitation machines with DC excitation coil and permanent magnets in the stator}

In this second family of hybrid excitation machines, we will find the hybrid excitation flux switching synchronous machine $[4,5,6]$ that are based on the principle of operating of the flux switching machine $[7,8,9]$ where the DC excitation coils were added.

This machine topology presents different advantages. The first one is its salient passive rotor, similar to that of a switched reluctance machine. The rotor contains neither permanent magnets nor windings (Fig. 7-a).

The second advantage of this machine is that all its active parts, permanent magnets and armature windings are located in the salient stator. Thus, all major sources of copper power losses are located in the stator that improves the efficiency of the cooling system. Moreover, in Fig. 7-b, it can be noticed that the permanent magnets are in focusing configurations that allows a high flux density values and high torque values. The armature windings are concentrated and located in open slots. In order to perform a high filling factor and to reduce armature end windings size, the armature winding can be realized outside the stator and then inserted in their locations. As known, using such a structure, like all permanent magnets synchronous machines, for applications that require expanded torque/speed characteristic, HEV for example, imposes the use of the flux weakening control strategy. Thus a direct component of the armature current is in- 
jected in the armature windings in order to weaken the excitation flux created by the permanent magnets. However, this control strategy has some drawbacks, e.g. the magnets may be forced to operate in the irreversible demagnetization region which could permanently demagnetize the magnets.

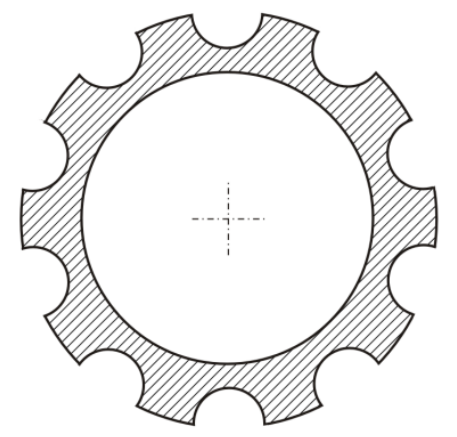

Fig. 7.a: Rotor of the hybrid excitation flux switching synchronous machine

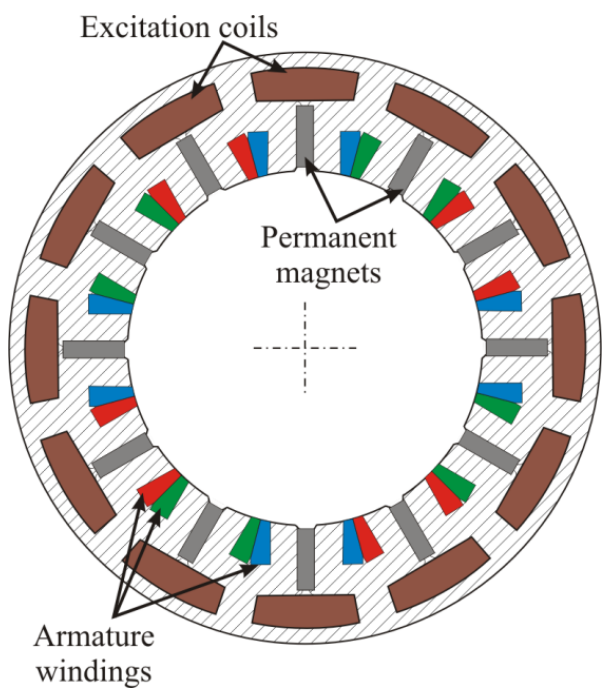

Fig. 7.b: Stator of the hybrid excitation flux switching synchronous machine

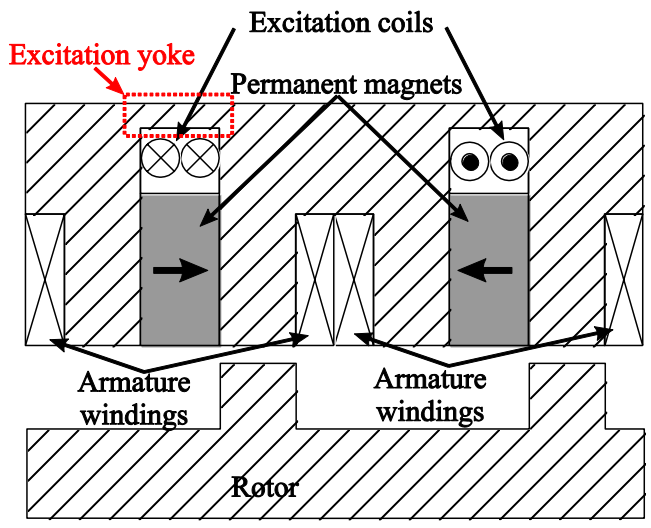

Fig. 8: Linear equivalent model of the switching flux hybrid excitation machine

In Hybrid Excitation Flux Switching Synchronous Machine (HEFSSM), armature windings and permanent magnet configurations remain the same as those of the flux switching synchronous machine. However, addition- al ferromagnetic parts are added such as the excitation yoke above the DC excitation coils. Though this part reduces flux in the air gap created by PM, it permits to canalizing the excitation coils flux. Thus, when the excitation coils are excited by a DC current, an additional flux, named DC excitation flux, is generated and is used to control the total excitation flux in the air gap of the machine.

In order to explain more clearly the operating principle of the HEFSSM, a part of the equivalent linear model of the machine is used. Fig. 8 shows this model and the different parts that constitute the HEFSSM.

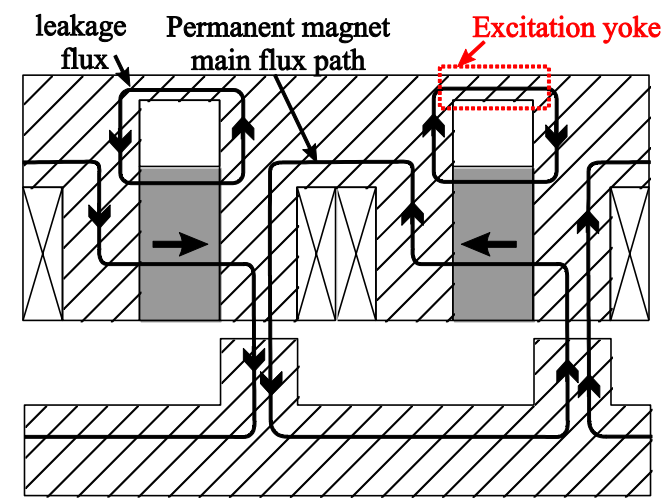

Fig. 9: Permanent magnets flux path when excitation current is null

When excitation coils are not excited by current, the flux generated by the permanent magnets can be divided into two parts: a first part will pass through the air gap region (permanent magnet main flux path in Fig. 9) and contributes to the energy conversion thus to the torque production. The second part is mainly constituted by leakage flux. In fact, in Fig. 9, we can notice that a part of the permanent magnet flux pass through the excitation yoke region.

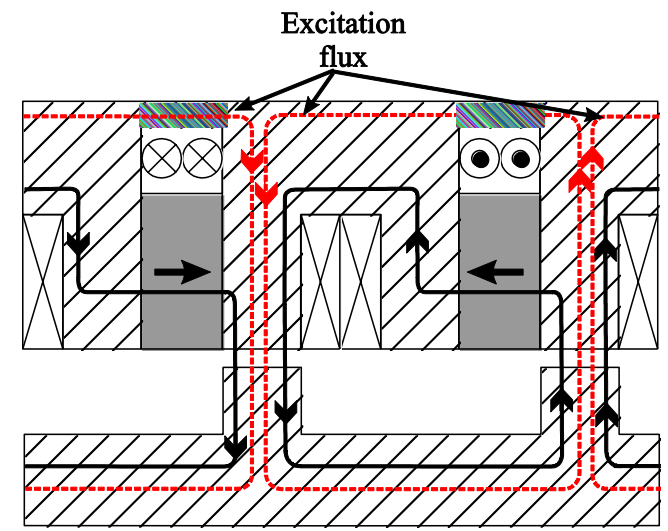

Fig.10-a: Permanent magnet and excitation coils flux paths Positive excitation current $\left(\mathrm{J}_{\mathrm{exc}}>0\right)$

The principle of the hybrid excitation of the studied structure is to use the DC excitation coils in order to generate flux that will reduce or increase (depending on the direction of the current in the excitation coils) the permanent magnets excitation flux in the air gap region. Thus, when the excitation coils are excited by an excitation current, they create an excitation flux that can increase or reduce the total excitation flux in the machine (see Fig. $10)$.

In order to obtain an efficient control of the total exci- 
tation flux in the air gap region of the machine, the ferromagnetic region located around the DC excitation coils must be correctly designed in order to reduce the needed excitation current to control the excitation flux and so to reduce the copper losses created by the excitation coils.

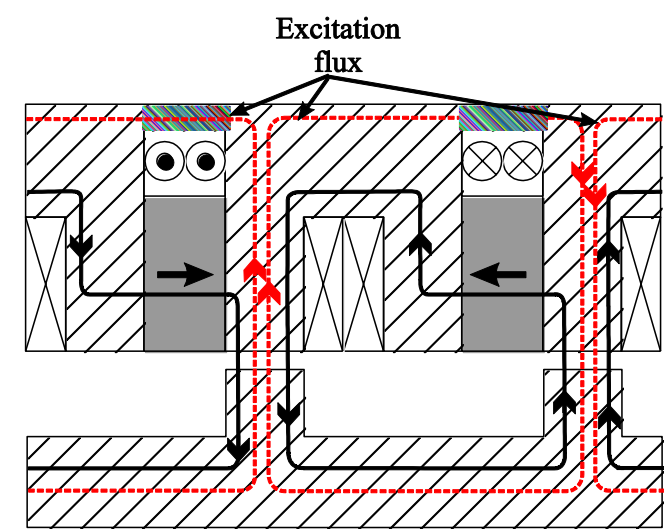

Fig. 10-b: Permanent magnet and excitation coils flux paths Negative excitation current $\left(\mathrm{J}_{\mathrm{exc}}<0\right)$

\section{DRIVING CYCLE}

In hybrid vehicle, the electric machine is sought in many different ways as we can see in Fig. 1, which represented the operating points for two sample cycles. The first is called "urban" and the second "road". They correspond to situations in response to a city traffic or traffic on a road or highway. In this article, we use the driving cycle (named NEDC driving cycle) obtained by considering a vehicle using the classical New European Driving Cycle "NEDC" that represents the typical usage of a car in Europe (Fig. 11).

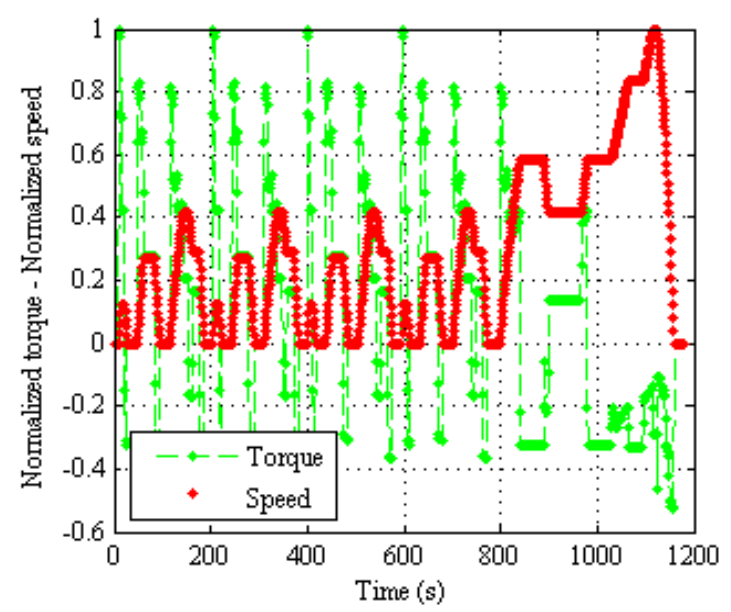

Fig. 11: NEDC driving cycle - Normalized torque and Normalized Speed versus time

The optimized design should allow to provide a machine structure minimizing two criteria that are contradictory: average losses on the driving cycle and the maximum RMS current supplied by the voltage inverter [10].

\section{MODELING ELEMENTS}

For this part, we are inspired by HEFSSM presented in [11] where authors have performed a parametric study in order to optimize the performances of the HEFSSM. This machine could produce the maximum torque of $210 \mathrm{Nm}$ and have a the maximum rotation speed of $20,000 \mathrm{rpm}$. It's external diameter of the stator is $264 \mathrm{~mm}$ and the length of the laminations is $70 \mathrm{~mm}$.

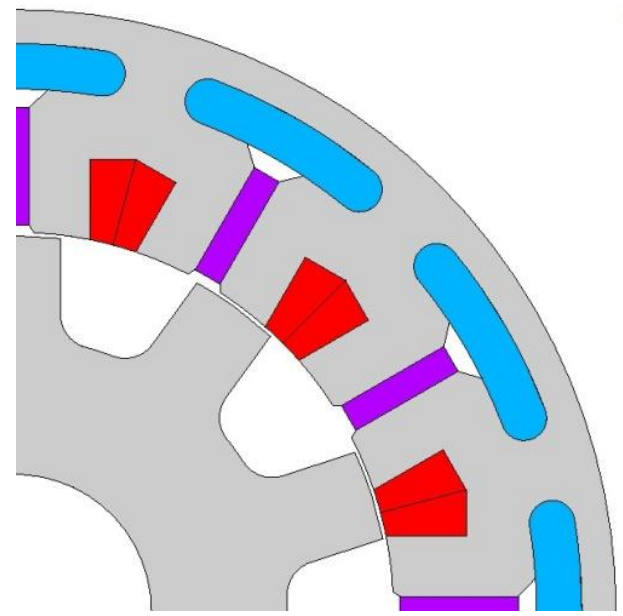

Fig. 12: Improved design proposed by [11]

\section{A. No-load flux}

Fig. 13 shows the evolution of the total no load excitation flux versus the angular position for different excitation current densities. It is important to notice that the generated excitation flux operates on both poles of the machine (south and north poles) without introducing neither a distortion nor a direct component in the sinusoidal wave form of the total excitation flux. This make the studied structure classified in the bipolar hybrid excitation machines [12].

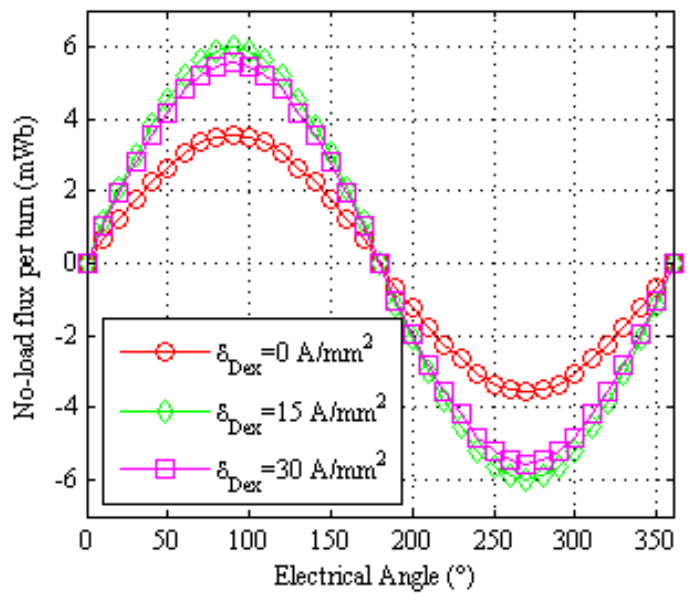

Fig. 13: Total excitation flux versus mechanical angle for different Excitation current densities

The evolution of the maximum no load total excitation flux evolution versus excitation current is presented in Fig. 14. We can notice that the total no load excitation flux reaches a maximum value (for a DC excitation current density around $14 \mathrm{~A} / \mathrm{mm}^{2}$ ) then it decreases when the excitation current increases. This is due to magnetic saturation phenomena in the stator of the HEFSSM. 


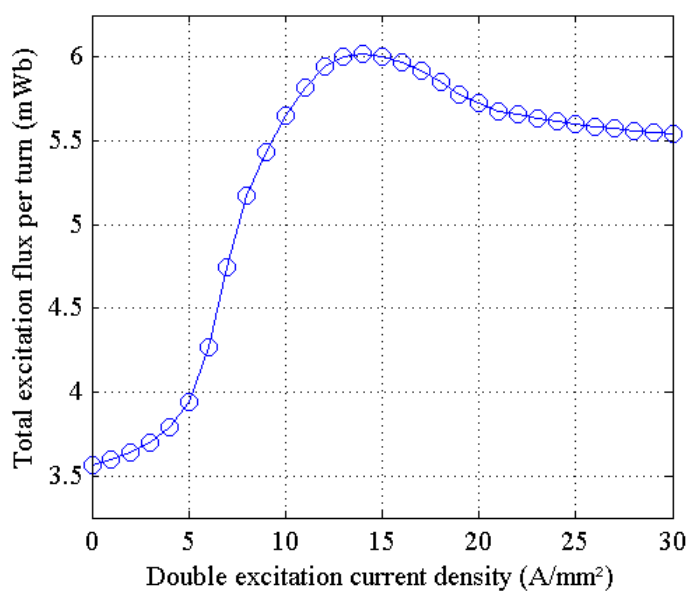

Fig 14: Total excitation flux per turn versus excitation current densities

\section{B. Torque}

In previous paragraph, we have seen that for DC current densities higher than $14 \mathrm{~A} / \mathrm{mm}^{2}$ the total no load flux is less than its maximum value. Nevertheless, in load operating cases it is important to notice that the average torque value still increases especially for high armature current density $\left(>30 \mathrm{~A} / \mathrm{mm}^{2}\right)$.

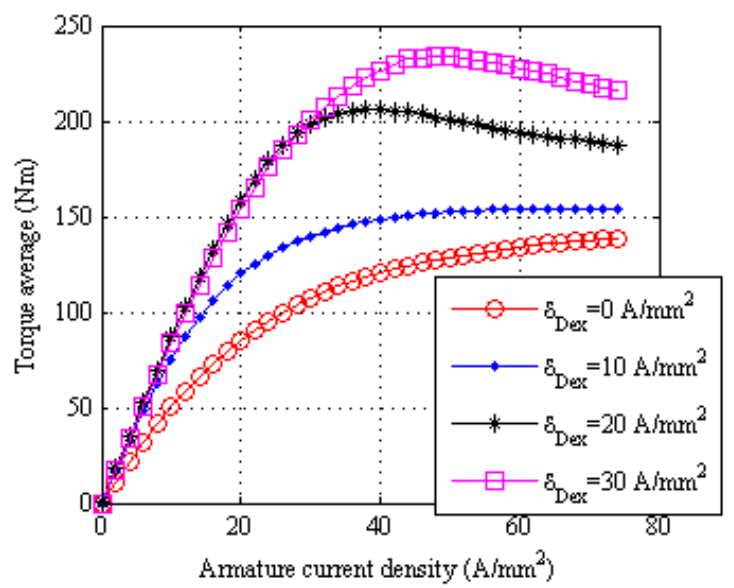

Fig.15: Torque average value versus excitation and armature current density

\section{Principe of computation of power losses}

In this section, the different power losses of the studied machine used for the NEDC driving cycle are presented. These losses are divided into two categories: copper losses and iron losses. Mechanical losses are not presented.

For each operating point of the driving cycle, the best command parameters are determined in order to reduce total power losses (copper losses plus iron losses). So as to find this optimal command, different solutions can be considered. One solution is to determine for each operating point, by using an optimization algorithm, the optimal command parameters: armature current density, excitation current density and command angle for the HEFSSM in order to minimize the total power losses for each operating point. Nevertheless, this solution requires executing many times 2D finite elements analysis (FEA) for each operating point (Ansys platform is used for simulation). knowing that the studied machine is highly saturated and the number of operating point is very important (1180 operating points), this solution is too time consuming and is eliminated (the computing time exceed the 6 months). The adopted solution consists of characterizing, by FEA, the studied machine for all possible command parameters combination. For each command triplet, the copper losses, iron losses, EMF value, in order to verify the DC maximum voltage constraint, and torque average value are determined. Then an optimization process is achieved in order to determine the optimal command parameters for each operating point of the driving cycle. Before presenting the obtained total power losses, the different parts of the machine's power losses are presented and the method of their computation is explained and discussed.

\section{1) Copper losses}

The copper losses are generated by the armature windings and are composed of a first part due to the current needed to reach the required torque, classically named the quadrature axis current component $\left(\mathrm{I}_{q}\right)$ in the Park transformation, and a second part due to the flux weakening current needed to reach the imposed speed and that is frequently used to reduce iron losses, classically named the direct axis current component $\left(\mathrm{I}_{\mathrm{d}}\right)$ in the Park transformation. For the hybrid excitation an additional copper losses part exists and is due to the DC excitation current.

\section{2) Iron losses}

The second part of the total power losses is the iron losses. In order to compute this quantity, the 2D FEA is used to compute the evolution of the total flux density versus rotor angular position for each element of the mesh of the stator and the rotor. This flux density was divided into 2 axes $\left(B_{\vec{r}}\right.$ and $\left.B_{\vec{\theta}}\right)[13]$ and computed in on-load conditions. Thus iron losses are determined by using the equations given below [14]. The first term of the equation 1 depends on the frequency and represents the classical hysteresis iron losses. The second term is the eddy current iron losses and is proportional to the square of the frequency. These two parts of the iron losses are computed for each "i" mesh element of the machine. Finally, it is important to notice that the stator and rotor iron losses are computed separately while the flux density for these two parts of the studied machines does not have the same electric frequency.

$$
\begin{aligned}
& L_{\text {iron } i, \vec{r} \text { or } \vec{\theta}}\left(W / m^{3}\right)=L_{h}+L_{e c} \\
& L_{h}=\left(k_{h 1} \Delta B_{p p i, \vec{r} o r \vec{\theta}}+k_{h 2} \Delta B_{p p i, \vec{r} o r \vec{\theta}) f}^{2}\right. \\
& L_{e c}=\frac{1}{T} \int_{0}^{T} \alpha_{p}\left(\frac{d B_{i, \vec{r}} o r \vec{\theta}}{d t}\right)^{2} d t
\end{aligned}
$$

Where: $\mathrm{k}_{\mathrm{h} 1}=5\left(\mathrm{~A} \mathrm{~m}^{-1}\right), \mathrm{k}_{\mathrm{h} 2}=50\left(\mathrm{~A} \mathrm{~m} \mathrm{~V}^{-1} \mathrm{~s}^{-1}\right)$ and $\alpha_{\mathrm{p}}=0.042\left(\mathrm{~A} \cdot \mathrm{m} \cdot \mathrm{V}^{-1}\right)$ for $330-35$ quality steel.

$\Delta B$ : Peak to peak value of the flux density 


\section{$B_{\vec{r}}$ : Radial component of the flux density \\ $B_{\vec{\theta}}$ : Ortho-radial component of the flux density}

Once iron losses are computed, it is possible to obtain the distribution of total iron losses density for the studied machine (e.g. Fig. 16). Finally, by computing the average value in each mesh element and the total average value, it is possible to determine the total iron losses in the studied machine.
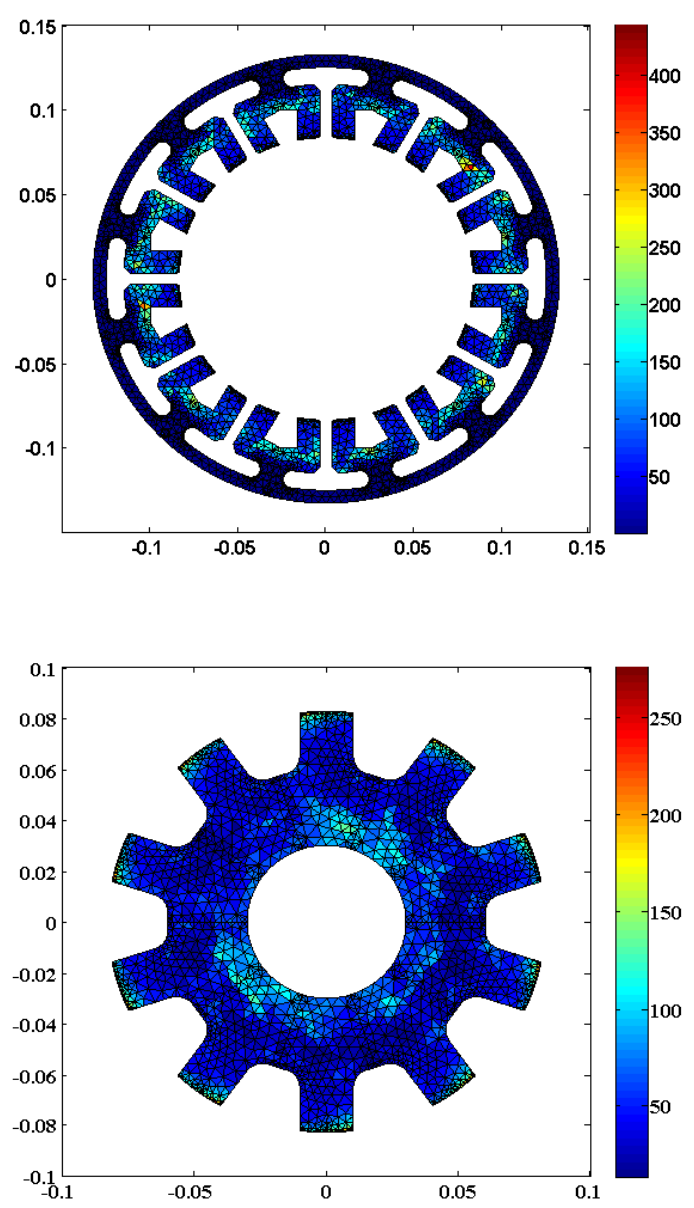

Fig.16: Iron power losses density (in $\mathrm{W} / \mathrm{kg}$ ) distribution in the rotor and the stator of the HEFSSM for $\mathrm{N}=4000 \mathrm{rpm}$, an armature current density equal to $30 \mathrm{~A} / \mathrm{mm}^{2}$ and an excitation current density equal to $30 \mathrm{~A} / \mathrm{mm}^{2}$.

For the HEFSSM, the iron losses depend on the DC excitation current, in Fig.17, the evolution of these two parts of losses are shown versus DC excitation current for $4000 \mathrm{rpm}$ speed value and an armature current density equal to $0 \mathrm{~A} / \mathrm{mm}^{2}$ and $25 \mathrm{~A} / \mathrm{mm}^{2}$..

We can notice that thanks to the added DC excitation current, the iron losses in the HEFSSM can be controlled and for an excitation current decreasing from 20 to $0 \mathrm{~A} / \mathrm{mm}^{2}$ it is possible to divide total iron losses by two times.
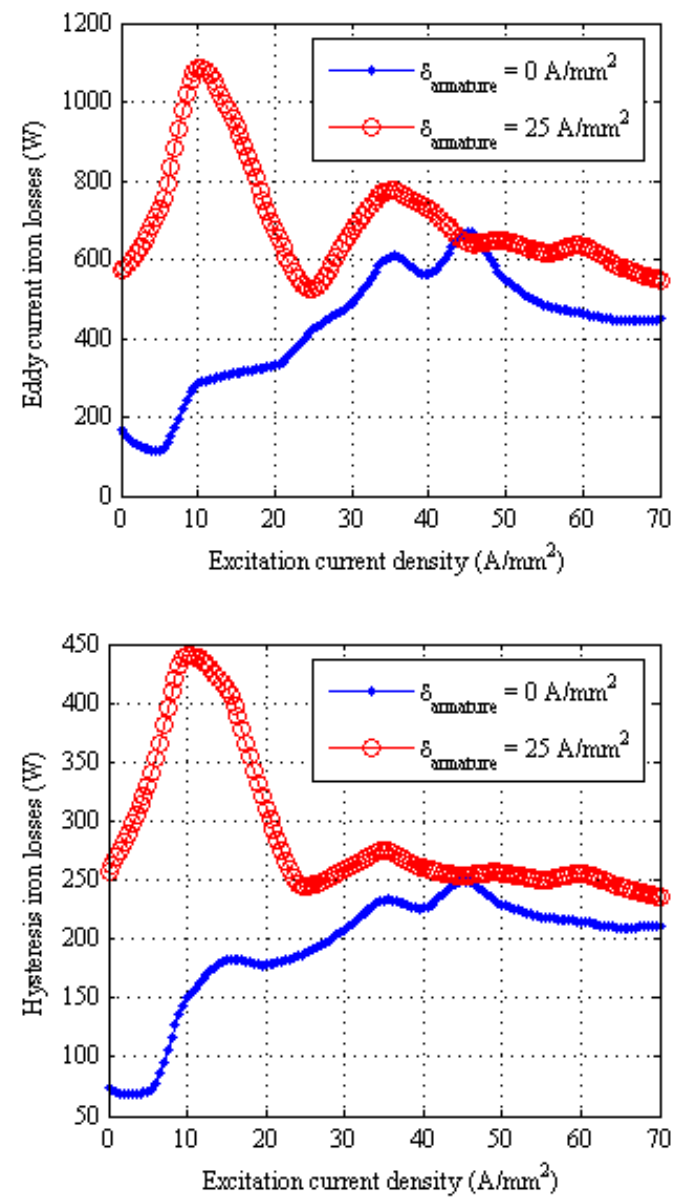

Fig. 17: Eddy current and hysteresis iron losses for $\mathrm{N}=4000 \mathrm{rpm}$ for different DC excitation current values and an armature current density equal to 0 and $25 \mathrm{~A} / \mathrm{mm}^{2}$

3) Summary of losses on a driving cycle

After presenting the models used to determine the torque and the different losses depending of control parameters, the values of optimal control parameters that minimizes the total of power losses are computed for each operating point of the NEDC driving cycle. In the following figures $(18,19,20)$, the evolution of the different losses are shown.

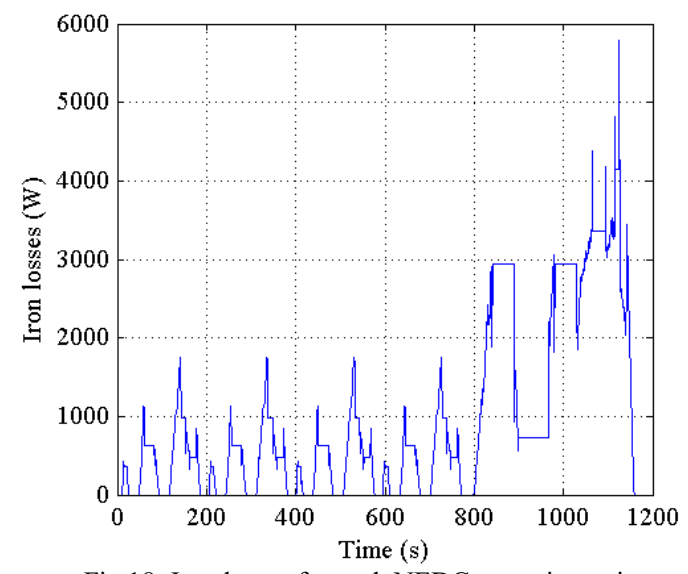

Fig.18: Iron losses for each NEDC operating point 


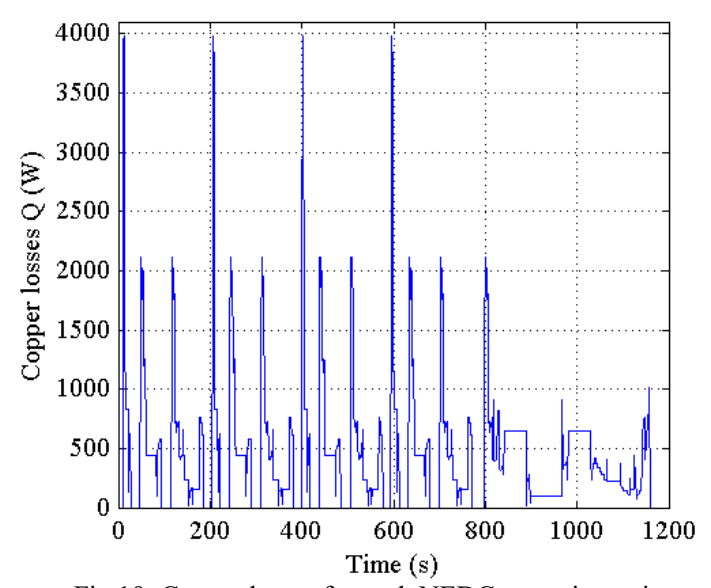

Fig.19: Copper losses for each NEDC operating point

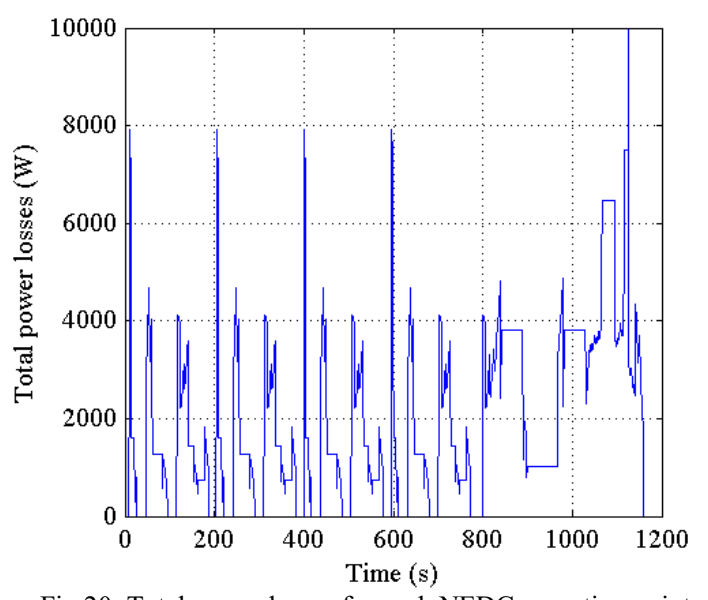

Fig.20: Total power losses for each NEDC operating point

The average power losses are computed and are given below:

- Average losses $=1915 \mathrm{~W}$

- Copper losses = $955 \mathrm{~W}$

- $(\mathrm{q}$ axis $=450 \mathrm{~W} ; \mathrm{d}$ axis $=65 \mathrm{~W}$; Exc. $=440 \mathrm{~W})$

- Iron losses $=962 \mathrm{~W}$

\section{OpTIMIZATION}

In an optimization process of an electrical machine, i.e. its geometric and magnetic parameters, by taking into account a real driving cycle for a hybrid electrical engine, must consider the optimization of the control parameters of this machine and in the same time the size of the static converter (by considering its apparent power (S) or the RMS value of the windings current). Even tough, the computation speed of actual computers is very high such an optimization problem is not possible to achieve while it needs several months (may be years) in order to converge and to obtain the optimal solution.

In order to reduce the computation time, it necessary to target the made calculations. For example, for determining the value of average torque, it is enough to make a dozen of FEA-2D simulations. Then in order to optimize the power losses on the driving cycle, it is necessary to choose judiciously enough current densities values to optimize computation time versus accuracy. In the case of the HEFSSM, the negative values of the excitation cur- rent density $\left(\delta_{\mathrm{e}}\right)$ are not needed because they are generating higher copper losses than the iron losses they are supposed to reduce. For the armature current used for the flux weakening $\left(\delta_{\mathrm{d}}\right)$, the maximum value is the value of the short circuit $\left(\delta_{\mathrm{cc}}\right)$ current density, which depends of the value of the excitation current density $\left(\delta_{\mathrm{e}}\right)$. To choose the maximum value of armature current for torque control $\left(\delta_{\mathrm{q}}\right)$, a discussion should be held with the designers of power electronics converter. Given that there is three control parameters for this electrical machine, the number of computation to be performed is equal to the cube of the number of the chosen control parameters. Currently, we study the influence of the value of discretization on the accuracy of the values of loss cycle, but a dozen of values seem a good compromise.

In order to further reduce the computation time, it is possible to simplify the used models for the optimization process. In fact, we can consider that the average torque is a function of ' $\delta_{\mathrm{e}}$ ' and ' $\delta_{\mathrm{q}}$ ' and that the iron losses are computed with load operating conditions and depend only of the excitation current density ' $\delta_{\mathrm{e}}$ ' and the total armature current density ' $\delta$ '.

For the determination of ' $\delta_{\mathrm{d}}$ ', we can apply the following formula [10]:

$$
\delta_{d}=\delta_{c c}\left(1-\frac{N_{b}}{N}\right) \text { for } \mathrm{N}>\mathrm{N}_{\mathrm{b}}
$$

With $\mathrm{N}$ : rotating speed

$\mathrm{N}_{\mathrm{b}}$ : base point rotating speed (here $4000 \mathrm{rpm}$ )

Finally, in order to accelerate the optimization process, the reduction of the number of points defining the operating cycle can be considered. We have seen that beyond about 500 points drawn randomly from the set of points defining the driving cycle, the values of average losses do not vary any more. Note that this solution provides a low gain in computing time, as we move from about 1000 to about 500 points. However, there are cycles defined by a number of points much more substantial, 10000 for example and dividing the number of used operating point by 20 will obviously improve the computation time.

For the geometric parameters to be used for the optimization process the seven parameters that was defined by the authors in [11] could be used and the value of the remanent induction of the magnets and the active length of the laminations may be added as optimization parameters.

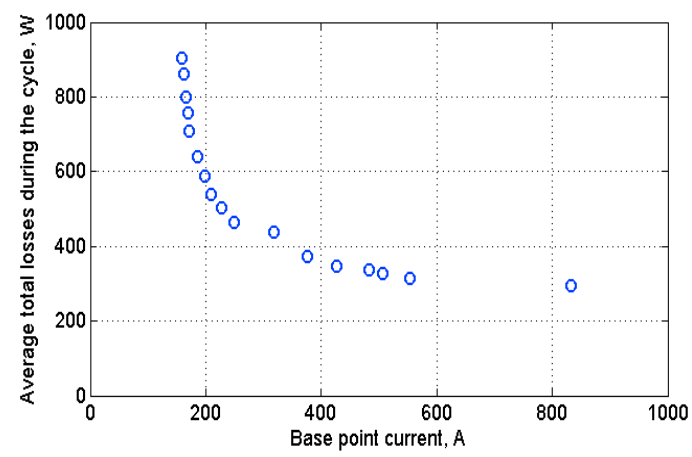

Fig. 21: Pareto curve result [10]

Finally, in order to perform this optimization process 
in reduced time, different multi-objective algorithms will be used such us the evolutionary algorithms, Swam particle algorithms or variational methods using the theory of random numbers. It will be possible to obtain the optimized geometric and electromagnetic parameters of the electrical machine by considering two contradictory optimization objective such us the armature RMS value and the total power losses. The optimal machines will form a "Pareto front" [10] as we can see on the figure 21.

\section{CONCLUSION}

In this paper we presented the study of a hybrid excitation synchronous machine designed for hybrid electrical or full electrical vehicle application. This machine combines two excitation flux sources: permanent magnets and DC excitation coils that are situated in the stator and the rotor is fully passive. For the studied application, the considered driving cycle was presented and it was shown that the required performances are highly variables. We presented with details the Hybrid Excitation Synchronous Machine Flux Switching (HEFSSM) for witch control parameters were optimized in order to optimize power losses for each operating point of the considered driving cycle. In [11], the authors have shown that this structure is potentially interesting for automotive applications. In deed the obtained power losses are relatively low and shows that this machine structure could be attractive for such an embedded application. Finally, the optimization process of the geometric and control parameters of this machine by taking into account driving cycles, total power losses and the sizing of the power electronics converters is discussed.

\section{REFERENCES}

[1] X. Luo and T. A. Lipo, "A synchronous permanent magnet hybrid AC machine". IEEE Transactions on Energy Conversion, vol. 15, $\mathrm{N}^{\circ}$ 2, June 2000, pp. $203-210$.

[2] Y. Amara, L. Vido, M. Gabsi, E. Hoang, A. H. Ben Ahmed, M. Lecrivain, "Hybrid Excitation Synchronous Machines: Energy Efficient Solution for Vehicle Propulsion". IEEE Transactions on on Vehicular Technology, vol. 58, issue 5, June 2009, pp. 2137 - 2149.

[3] T. Kosaka, and N. Matsui, "Hybrid excitation machines with powdered iron core for electrical traction drive applications". Electrical Machines and Systems, 2008. ICEMS 2008. p.p. $2974-2979$.

[4] E. Hoang, M. Lecrivain, M. Gabsi, '’A new structure of a switching flux synchronous polyphased machine with hybrid excitation'. EPE-2007 Conference, Aalborg, September 2007

[5] E. Hoang, S. Hlioui, M. Lecrivain, M. Gabsi, "Experimental study of lamination material, case of switching flux synchronous machine with hybrid excitation." European Conf. on Power Electronics and Appl., EPE-2009, Barcelona.

[6] E. Hoang, M. Lecrivain, M. Gabsi, ''Flux switching dual excitation electrical machine". PCT/EP2007/052167 March 8, 2007. International patent.

[7] E. Hoang, A. H. Ben Ahmed, J. Lucidarme, 'Switching flux permanent magnet polyphased synchronous ma- chines". Proc. of 7th European Conference on Power Electronics and Applications, vol. 3, 903-908, 1997.

[8] E. Hoang, M. Lecrivain, M. Gabsi, B. Multon, "Influence of magnetic losses on maximum power limits of synchronous permanent magnet drives in flux-weakening mode." Proc. IEEE Industr Applications Society Annu. Conf, 2000, Vol. 1, pp. 299-303.

[9] Zhu, Z.Q. Pang, Y. Howe, D. Iwasaki, S. Deodhar, R. Pride, A., "Analysis of Electromagnetic Performance of Flux-Switching Permanent-Magnet Machines by Nonlinear Adaptive Lumped Parameter Magnetic Circuit Model." IEEE Transactions on Magnetics, November 2005, Issue 11, Vol. 41, pp. 4277-4287.

[10] P. H. Nguyen, E. Hoang, M. Gabsi, ' 'bi-criteria optimization design of an interior permanent magnet synchronous machine for hybrid electric vehicle application'. Electrimacs-2011, 6-8th June 2011, Cergy-Pontoise, France.

[11] E. Sulaiman, T. Kosaka, Y. Tsujimori, N. Matsui, 'Design of 12 slot 10 pole Permanent Magnet Flux Switching Machine with hybrid excitation for hybrid electric vehicle". 5th IET International Conference on Power Electronics, Machines and Drives (PEMD 2010), 19-21 April 2010, Brighton, UK.

[12] Vido, L. Gabsi, M. Lécrivain, M. Amara, Y. Chabot, F.,"Homopolar and bipolar hybrid excitation synchronous machines." Electric Machines and Drives, 2005 IEEE International Conference on, May 2005, pp. 1212-1218.

[13] Zouzou, S., Kedous-Lebouc, A. and Brissonneau, P., "Magnetic properties under unidirectional and rotational field." Journal of Magnetism and Magnetic Materials 112, 1992, pp. 106-108.

[14] Hoang, E., Multon, B. and Gabsi, M., "Enhanced accuracy method for magnetic loss measurement in switched reluctance motor." ICEM, December 1994. 